\title{
Which aspects of engineering degrees do graduates most value in their working lives?
}

Keywords: graduate, education, employability, engineering

\section{Author Information}

Gareth Thomson, Aston University, UK, https://orcid.org/0000-0002-7104-4348

How to cite this article:

Thomson, Gareth. "Which aspects of engineering degrees do graduates most value in their working lives?” Információs Társadalom XX, no. 2 (2020): 132-141.

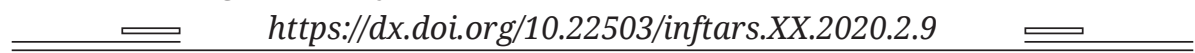

All materials

published in this journal are licenced

as CC-by-nc-nd 4.0 


\section{Introduction}

When developing curricula for engineering degree programmes, the teams involved have to weigh up the demands from a range of stakeholders. Very often these will include the need to conform to the requirements of a national or international professional body such as ABET (ABET 2018) in the United States or the Engineering Council in the UK (Engineering Council 2014). These bodies will normally define the core academic requirements of professional engineers which in turn may be tied into the competencies associated with the graduates achieving professional registration. Employers at local and national level will also have an influence in the shape and content of programmes either through direct dialogue in industry advisory boards or more indirectly by observing the recruitment patterns of graduates (Lundberg et al. 2018, Sui et al. 2018). 'Employability' is also a much used term in the design of programmes and covers not only the technical engineering competencies expected of graduates but also incorporates many of the personal and interpersonal skills expected of graduates in the workplace. Together with 'sustainability', 'employability' has become arguably one of the key drivers for curriculum shift over the last decade (Kolmos et. al. 2016, O'Leary 2017, Sin et. al. 2019).

Students and potential students are also key influencers in ensuring programmes are commercially attractive and thrive in competitive educational marketplace (Lee \& Chin 2017, Morgan, M., Direito 2018). While for students, accreditation and employability will be key factors in their choice of degree so too will be methods of teaching and specific programme focus together with more general factors such as city, institutional reputation, social and costs. (Olmos et. al. 2014, Skatova 2014)

While these factors are all important, they tend to take a predictive approach to curriculum design. They tend to be a best measure of what academics, industrialists and accrediting bodies feel should be the learning outcomes to help furnish graduates with the sorts of knowledge, skills and understanding they might need at some point in the future. This approach, together with other measures such as student surveys tend not to close the loop and check to see if the curriculum succeeded in its aims and if the degrees truly equipped their graduates effectively for their desired career.

It can therefore be argued that a key influencer should be the graduates of the degrees. These individuals have experienced the degree programmes and having transitioned into a graduate role are in the best position to appraise how relevant and useful the degree and its elements were to them in terms of providing the skills needed (Scott 2014, Staffan 2010, Stiwne 2010, Feutz 2012).

This paper therefore looks at this issue and asks "Which aspects of engineering degrees do graduates value most in their working lives?” 


\section{Method}

\subsection{Methodology}

A survey of engineering graduates from a set of programmes was therefore carried out.

The online survey was chosen as a practical approach to ensure both the anonymity of the respondents and the efficient and consistent gathering of data for a geographically disparate group of individuals.

Formal approval for the survey and associated analysis methodology were sought and granted by the Aston University Engineering and Applied Science ethics committee.

\subsection{The Survey}

While the survey focussed on the experiences of a particular degree family at a specific UK University, to offer transferability of lessons learned by this work, the survey was structured to draw on key components of many engineering degree programmes.

The survey therefore looked at 5 elements which feature in many engineering degrees:

- Conventionally taught core engineering science and mathematics (Classic engineering science subjects such as solid mechanics, thermodynamics, fluid dynamics etc.)

- Applied engineering science (CAD / Manufacturing / Quality / Societal and commercial aspects etc.)

- Project based learning (PBL) (Projects, often with an element of design, build and test in which students, commonly working in groups, engage in structured projects to achieve specific learning outcomes.)

- Major final year project / dissertation (Final Year Project (FYP) - individual academic year-long project)

- Industrial internship / placement (Year long placement in industry)

- In addition the survey had three sections in which the data was actually gathered.

- Demographics: This section featured basic information on when the individual participating in the survey graduated, the industry sector in which they work and their current role.

- Main content: for each of the 5 programme elements students were asked if they used the content taught directly, if it underpinned what they did in their work even if not used directly and if the element developed transferable skills used in their current role. This was done via a 5 point Likert scale in each case and participants could add further comments if desired. 
- Further comments: Participants were offered a more open opportunity to discuss areas of the curriculum they would have liked to have added, to have dropped or make any other comments.

\subsection{Participants}

The graduates who participated in this study were sourced via the author, a former programme director's "Linkedin" network. The participants had all graduated with Bachelor or integrated Masters degrees from the Mechanical Engineering family of undergraduate programmes at the parent University over the previous decade.

Participants who graduated 6 or more years ago followed a relatively traditional curriculum focussed around lectures, structured tutorials and laboratories. Design and more open ended practical work was however relatively limited. A more project based learning (PBL) focus following CDIO principles was introduced for the more recent graduates. CDIO is an educational framework stressing engineering fundamentals set in the context of Conceiving - Designing - Implementing - Operating (CDIO) real-world systems and products and can therefore commonly feature design, build, test type project activity to support learning (Crawley et al. 2014, Edstrom \& Kolmos 2014). In addition to the projects embedded in the taught degree, the University also encourages students to undertake a year long industrial placement mid-degree with a little over half of the cohort generally taking this option up.

Approximately 80 former students were approached with 32 volunteering to complete the study. 20 of the students graduated over the last 5 years and followed a programme with significant PBL content with 12 graduating 6 years or more ago and following a more traditional curriculum. 16 of the 32 total took a year long industrial placement with this figure being proportionately slightly less than the full cohort mean for this option.

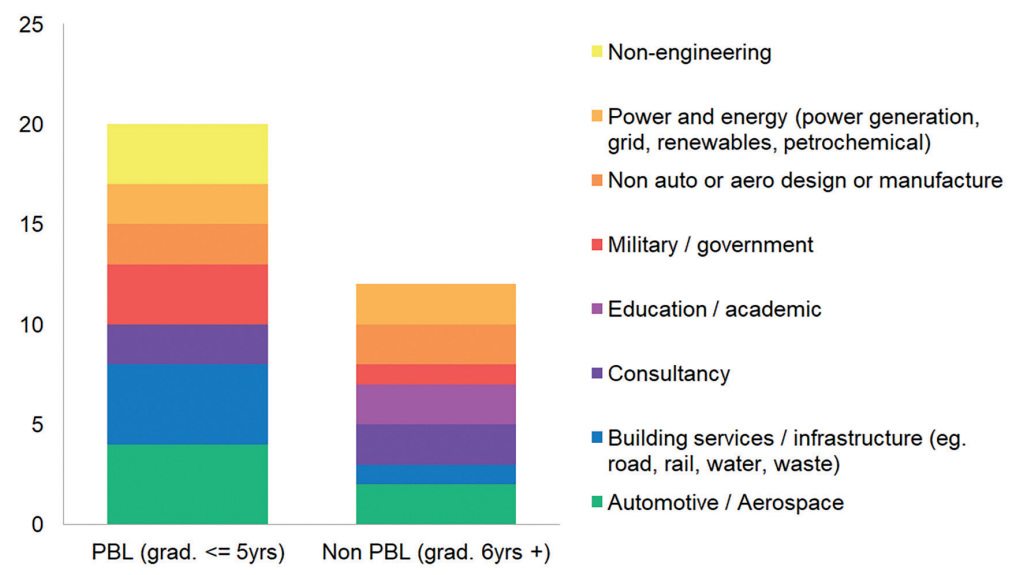

Figure 1. Industrial Sectors of Graduates Participating in Survey 
Mechanical engineering is a very broad degree. The result of this is that the graduates produced can have a very diverse range of careers, in a wide variety of industry sectors and this was reflected in the professional roles of those surveyed. A breakdown of the industry sectors in which the graduates who took part in the survey operate in can be seen in figure 1.

\section{Results}

Figures 2 to 4 show the collated results of the investigation. In each case the graduates were asked, for each of the five programme elements, whether in their daily work they used these directly, whether they underpinned what they did and whether the modules helped them develop the transferrable personal and professional skills needed in their role.

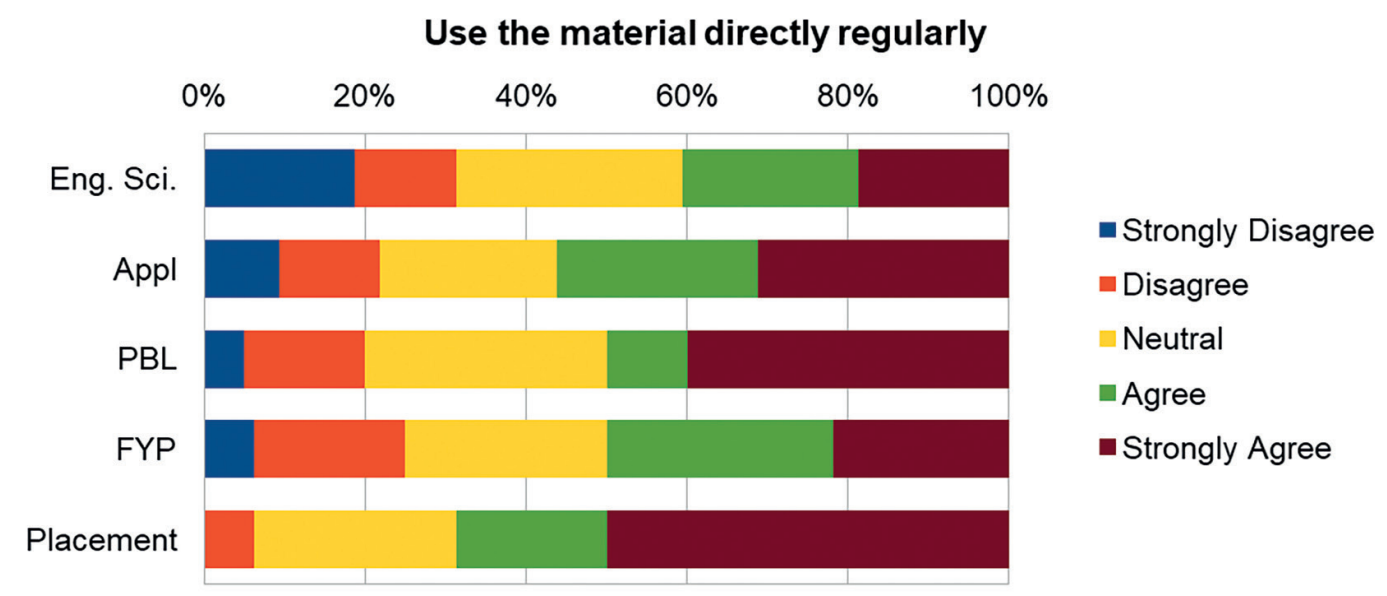

Figure 2. "I use some of the formally taught knowledge and skills gained in (programme element) directly on a regular basis"

Figure 2 shows the extent to which graduates felt they directly used the material taught to them in each of the programme elements. A noteworthy observation is that for the classic engineering science modules which form a significant part of most degrees, relatively few students call on this first principles knowledge at the core of these modules directly on a day to day basis. Other areas including PBL and applied engineering sections also hover around $50 \%$ of responses clearly positive. This might not be unexpected given the range of diverse and specialist roles Mechanical Engineering graduates in particular find themselves in where the regular application of the basic broad fundamentals are more likely to be surpassed by industry specific tools and techniques. For some however, particularly those working in perhaps research areas, core skills will still be key to aid in the solving of non-standard 
problems. This can be seen by a comment from a graduate working in research and development in the power generation sector:

"I use the skills learned in Solid Mechanics, Thermofluids, Heat Transfer, Engineering mathematics, Turbomachinery on a daily basis."

And from another;

"The strong focus on numerical problem solving... has greatly aided me in my career...."

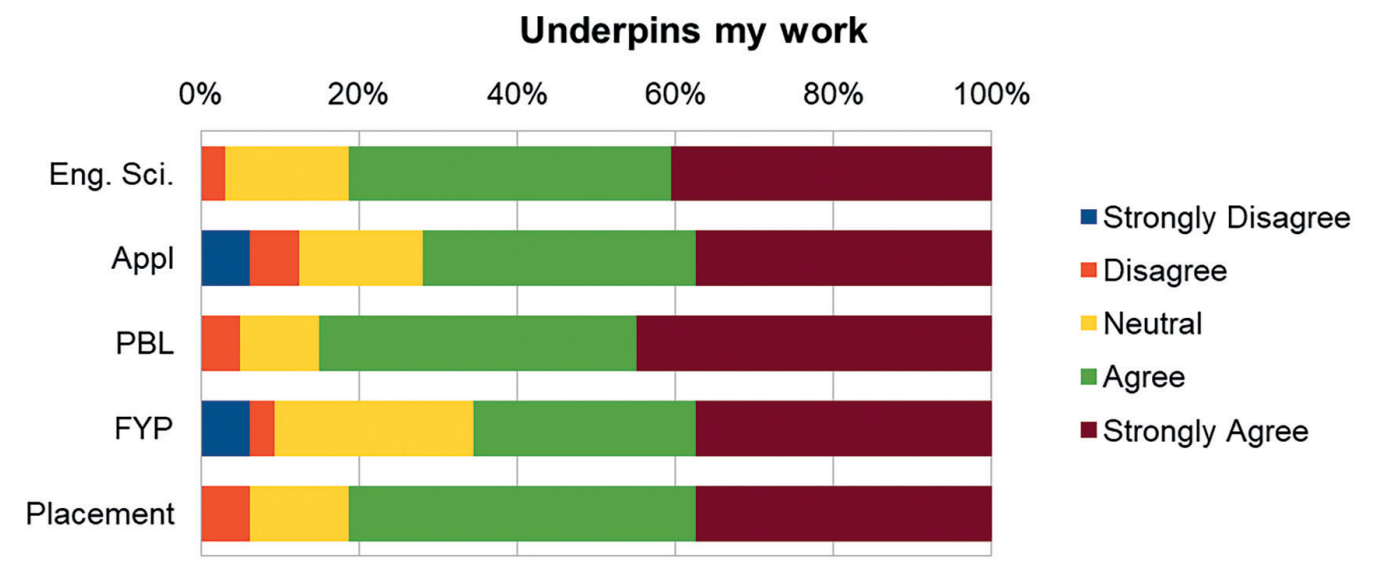

Figure 3. "Whether or not I use the knowledge formally gained in (programme element) directly, I feel it underpins much of my daily work"

Figure 3 shows that the graduates appreciated that even if they may not use the formal learning in a direct sense on a day to day basis they appreciated that derivatives from this work informed their role and added to the depth of understanding of their current processes.

From a graduate working in the military / government sector:

"While I do not use all of the skills directly they have enabled me to become a CEng (Chartered Engineer) and allow me to retain a level of credibility when discussing technical subjects.”

From another with a similar opinion:

"The tacit knowledge, vocabulary and understanding is invaluable as an aid for working alongside engineers with a deep technical specialism and translating / facilitating their conversations with the business functions."

Figure 4 shows the impact of those transferrable skills elements which featured in the degree programmes and which help to develop the wider personal and interpersonal qualities of the individual. It was clear that graduates felt this was important and had been a positive support to their career. In particular the project based learning element and the placement were reviewed very positively in this area with in both cases around three quarters of graduates strongly agreeing that it had helped them feel comfortable with more general problem solving, organisational, investigation or personal and interpersonal skills in their daily work. 


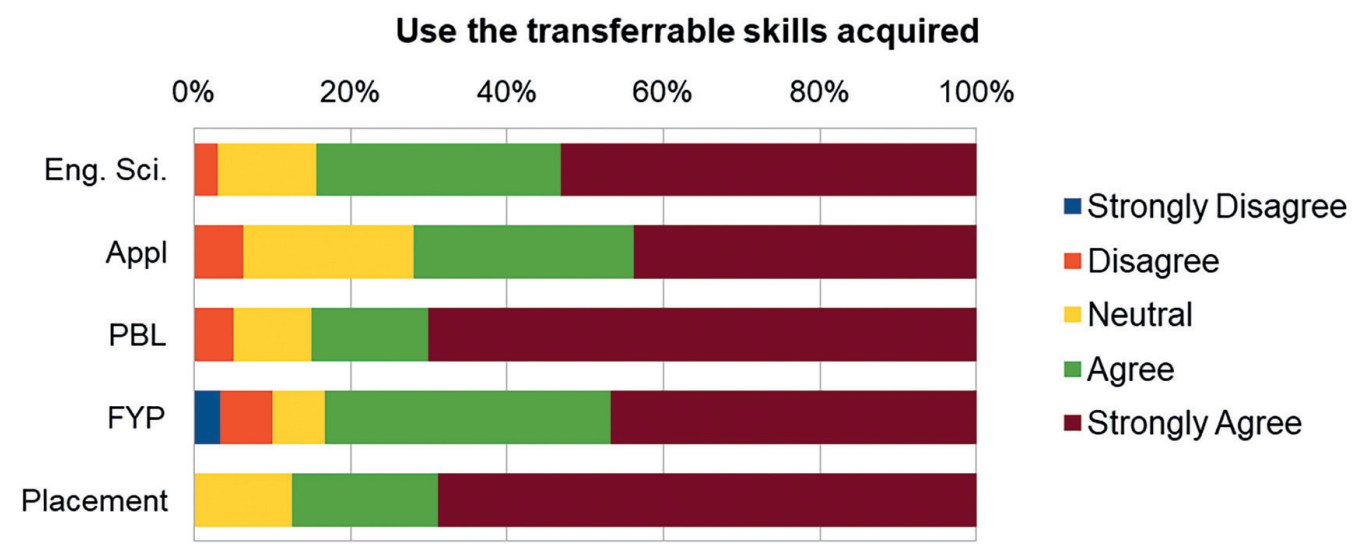

Figure 4. "The (programme element) helped me feel comfortable with more general problem solving, organizational, investigation or personal and interpersonal skills in my daily work"

In regard to the PBL elements some comments from surveyed graduates included:

"....provide a link into reality of engineering problem solving and team work. This section of the degree provided good foundation for project / schedule management skills, working within teams and general applied engineering" and

"The skills garnered in PBL have been a constant part of my tool set as I have progressed through my career."

In relation to the placement experience many of the respondents also reflected positively on its importance to their personal development:

"(the placement) ... massively increased my knowledge and improved my professional development and individual development."

And

"Placements are a must for good engineering development and progressing into industry. Additionally the placement provided an industrial mind-set for the final year of study and gave relevance to the final year module structure. "

The students involved in this study graduated over the course of a decade. While the programme structure and detail content varied and evolved over this time, the core elements of engineering science, applied engineering topics, final year project together with the option of an industrial placement were constant. Midway through the decade a major change was the introduction of project based learning elements designed to make the learning more effective and industry focussed. As part of this work we wanted to see if this new element was valued.

Figure 5 shows aggregated results for students on the older, traditional programme versus those on the more recent PBL aided model. For each programme element a comparison has been drawn by aggregating all the Likert responses which indicated use / neutral / limited or no use for direct / underpinning or transferrable skills in the graduates current working role. 


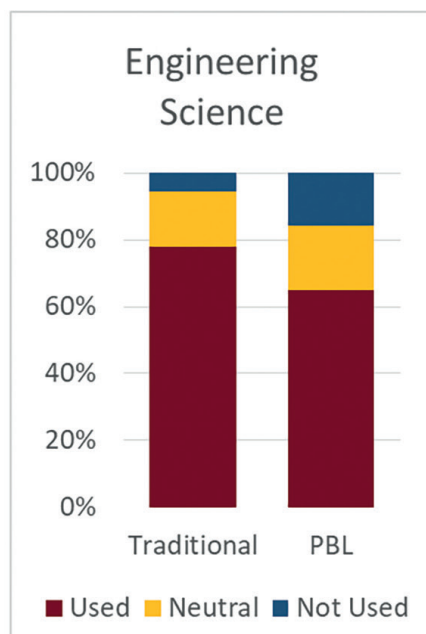

(a)

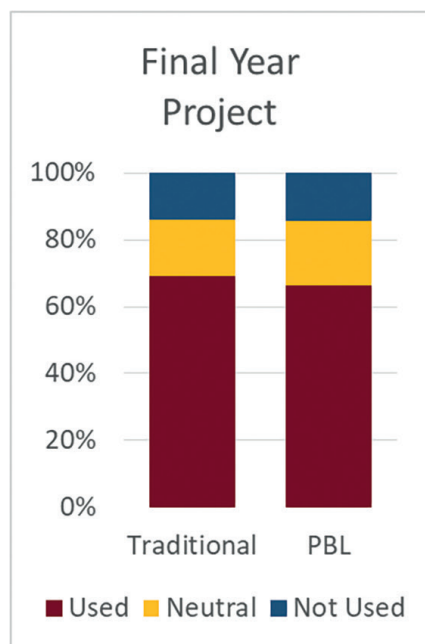

(b)

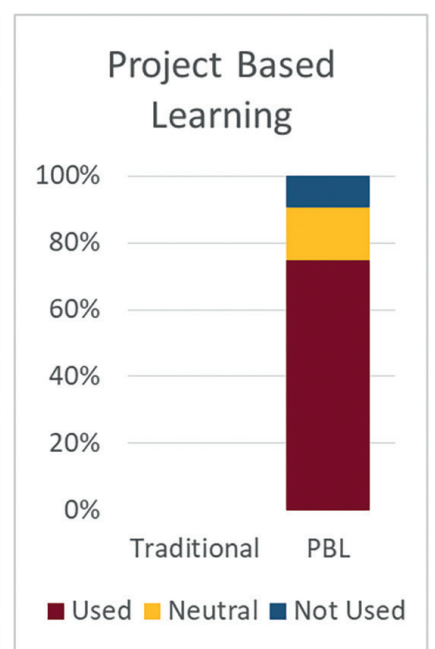

(c)

Figure 5. Aggregate comparison of reflections of three programme elements as featured in the traditional and PBL focused degrees.

For the engineering science element (Fig 5(a)) there does appear to be some slight dropping away of the use to which the more recent graduates place on this. A similar pattern was also observed in the applied engineering section. The follow up interviews will explore this issue to investigate whether this is a genuine trend, a statistical blip given the relatively small numbers surveyed or is related to the increased emphasis on PBL in the newer degree. The project based learning element has been well received and its relevance to graduates as can be seen in Fig. 5(c). By contrast Fig 5(b) shows a very consistent appraisal of the relevance of the final year project over time.

\section{Discussion and Summary}

Graduates are the key outcome of engineering degree programmes and delivering relevant curricula is important to ensure those graduates are equipped for their professional lives. Academic teaching teams work hard to try to deliver effective programmes, balancing constraints of resource with the demands of a range of influencers whether these be their own institutions policies, accrediting bodies, current and future students, external examiners and industrial boards. Graduates themselves, the consumers of the programmes and those who have direct experience of taking the learning into industry are often not part of many formal review processes.

This work has taken some steps in this direction. It shows that, for the graduates participating in the survey, taking a degree has been important in preparing them for and supporting them in their work life. All components of a 
degree programme whether the conventional engineering science, placement or final year project deliver direct, underpinning or transferrable skills giving positive benefits to graduates in the workplace.

It does however also pose some possible questions.

While the results were generally highly positive there were some students who reported less than optimum and negative responses for some aspects of some programme elements. It may be that this may be inevitable given the broad range of sectors and roles to which graduate mechanical engineers may go to - a perfect course for a mechanical engineering graduate moving into the rail sector is unlikely to similarly suit a classmate moving into the manufacturing or biomedical engineer sector.

For analysis and transferability, the programme used in the study was broken down into five programme elements common to many degrees. While this was an efficient way to segment the degree it also needs to be recognised that in doing so each element was characterised by a blend of both different content types and different learning modes. Isolating the effectiveness and relative importance of these two aspects of each element will be explored in future interviews.

It is intended that this work will be expanded and explored further. Semi-structured interviews will be carried out to explore and deepen the understanding of some of the issues raised. This will also look at longitudinal issues to reflect that over a decade, regardless of internal issues of content and format within a programme, the students embarking on their studies together with employment market and societal issues will also change and these could also be reflected in graduate views on the merits and suitability of their degree.

\section{References}

ABET Engineering Accreditation Commission, Criteria for Accrediting Engineering Programs, ABET, 2018.

Crawley, E.F., J. Malmqvist, S. Östlund, D. Brodeur, K. Edstrom. "Rethinking Engineering Education: The CDIO Approach.” Springer Verlag, 2018.

Edström K., A. Kolmos. "PBL and CDIO: complementary models for engineering education development.” European Journal of Engineering Education, 39, no. 5 (2014): 539-555, https:/l doi.org/10.1080/03043797.2014.895703 
Engineering Council. “UK-SPEC, UK Standard for Professional Engineering Competence.” Engineering Council, 2014.

Feutz, M., R. Zinser. “Following Engineering Graduates.” Journal of Technology Studies 38, no. 1 (2012): 12-22.

Guàrdia Olmos, J., M. Peró Cebollero, A. Jorge Hervás et al. "Factors related with the university degree selection in Spanish public university system. An structural equation model analysis” Quality \& Quantity 49, no. 2 (2015): 541-557.

Kolmos, A., R. G. Hadgraft, J. E. Holgaard. "Response strategies for curriculum change in engineering”, Int J Technol Des Educ 26 (2016): 391.

Lee, C.-C., S.-F. Chin. 'Engineering Students' Perceptions of Graduate Attributes: Perspectives From Two Educational Paths', IEEE Transactions on Professional Communication 60, no. 1 (2017): 42-55. https://doi.org/10.1109/TPC.2016.2632840.

Lundberg G.M., A. Gaustad, B. R. Krogstie. "The employer perspective on employability IEEE Global Engineering Education Conference (EDUCON)”, 909 - 917, 2018.

Morgan, M., I. Direito. The employment expectations of Masters Engineering students, 3rd International Conference of the Portuguese Society for Engineering Education (CISPEE) Portuguese Society for Engineering Education (CISPEE), 2018 3rd International Conference of the. 1-5, Jun, 2018.

O’Leary, Simon. “Graduates’ Experiences Of, and Attitudes Towards, the Inclusion of Employability-Related Support in Undergraduate Degree Programmes; Trends and Variations by Subject Discipline and Gender.” Journal of Education and Work 30, no. 1 (2017): 84-105.

Scott, B. "Graduate attributes and talent perceptions: Reflections on the first year of graduate employment.” International Journal of Employment Studies, no. 1 (2014): 39.

Sin, C., Tavares, O., \& Amaral, A. "Accepting employability as a purpose of higher education? Academics' perceptions and practices.” Studies in Higher Education, 44, no. 6 (2019): 920.

Skatova, A., E. Ferguson. "Why do different people choose different university degrees? Motivation and the choice of degree." Frontiers in Psychology 5, Article 1244 (2014).

Staffan, N. "Enhancing individual employability: the perspective of engineering graduates." Education + Training 6, no. 7 (2010): 540. https://doi.org/10.1108/00400911011068487.

Stiwne, E., T. Jungert. "Engineering students' experiences of transition from study to work.” Journal of Education and Work 23, no 5 (2010): 417-437.

Sui F. M., J. C. Chang, H. C. Hsiao, S. C. Chen, D. C. Chen. "A Study Regarding the Gap Between the Industry and Academia Expectations for College Student's Employability 2018 IEEE International Conference on Industrial Engineering and Engineering Management (IEEM) “ 1573 - 1577, 2018. 